\title{
ESCOLARIZAÇÃO PARA A INCLUSÃO: FORMAÇÕES IMAGINÁRIAS E ACONTECIMENTO DISCURSIVO
}

Hildete Pereira dos Anjos (Unifesspa)*

\begin{abstract}
RESUMO
O artigo tem como objetivo analisar, no discurso pedagógico acerca da deficiência, as formações discursivas que se produzem a partir do encontro entre formações imaginárias e acontecimento discursivo, conforme formulação de Pêcheux. O corpus foi constituído por materiais produzidos por grupos focais, dos quais participaram docentes de salas de recursos, de salas comuns, técnicos e gestores da educação especial. Compreende o processo discursivo como composto por jogos de sentido regulados cultural e historicamente. Em tais jogos, analisando-se os lugares de onde falam aqueles que descrevem as salas de recursos e o lugar do outro em tais descrições, assim como as circunstâncias em que tal acontecimento discursivo ocorre, são explicitadas relações que evidenciam a heterogeneidade do discurso pedagógico sobre inclusão, o qual oscila entre o autoritário e o polêmico.
\end{abstract}

Palavras-chave: Análise de discurso. Deficiência. Políticas públicas.

\section{ABSTRACT \\ SCHOOLING FOR INCLUSION: IMAGINARY FORMATIONS AND DISCURSIVE EVENTS}

The article aims to analyze, in the pedagogic discourse about the disability, the discursive formations that are produced from the encounter between imaginary formations and discursive event, as formulated by Pêcheux. The corpus consisted of materials produced by focal groups, which included lecturers from support rooms, common rooms, technicians and special education managers. It understands the discursive process as composed of sense games that are culturally and historically regulated. In such games, analyzing the places where those who describe the resource rooms and the place of the other in such descriptions, as well as the circumstances in which such a discursive event occurs, are analyzed, relations that evidence the heterogeneity of the pedagogical discourse on Inclusion, which oscillates between authoritarian and controversial.

Keywords: Discourse analysis. Disability. Public policies.

\section{RESUMEN}

\section{LA ESCOLARIZACIÓN PARA LA INCLUSION: FORMACIONES IMAGINARIAS Y ACONTECIMIENTO DISCURSIVO}

El artículo pretende analizar, en el discurso pedagógico sobre la discapacidad, las formaciones discursivas que se producen desde el encuentro entre formaciones

\footnotetext{
* Doutora em Educação pela Universidade Federal da Bahia (UFBA). Professora na Universidade Federal do Sul e Sudeste do Pará (Unifesspa). Membro do Grupo de Estudos Dinâmicas Socioeducacionais, Políticas Públicas e Diversidade (GEDPPD/ CNPq). E-mail: anjoshildete@unifesspa.edu.br
} 
imaginarias y acontecimiento discursivo, como ha formulado Pêcheux. El corpus consistió en materiales producidos por grupos focales, de que participaron maestros que actúan en salas de recursos multifuncionales, salas comunes, técnicos y gestores de la educación especial. El proceso discursivo consiste en juegos de sentido regulados por la cultura y por la historia. En este tipo de juegos, analizando los lugares en los que hablan son las que describen las salas de recursos y el lugar de otro en tales descripciones, así como las circunstancias en las que ocurre tal acontecimiento discursivo, son explicitadas relaciones que muestran la heterogeneidad del discurso pedagógico en la inclusión, que oscila entre el autoritario y el controvertido.

Palabras clave: Análisis de discurso. Discapacidad. Políticas públicas.

\section{Introdução'}

Este trabalho questiona o funcionamento do discurso pedagógico em torno da temática da inclusão da pessoa com deficiência na escola. Sendo produto de práticas humanas, e se constituindo ele próprio numa prática, o discurso tem modos particulares de funcionamento, originados das formações ideológicas em que estão imbricados (PÊCHEUX, 1997). Os modos de funcionamento do discurso pedagógico, portanto, estariam imbricados com suas condições materiais de produção (os processos educacionais vividos), assim como condições ideológicas de produção.

Foram analisados textos transcritos de grupos focais ${ }^{2}$ que debateram três eixos temáticos acerca da Política Nacional de Educação Especial na Perspectiva Inclusiva (BRASIL, 2010): avaliação do aluno, formação do professor e funcionamento das Salas de Recursos Multifuncionais. As discussões nos grupos foram gravadas e transcritas; como não houve intenção comparativa entre as experiências das duas redes públicas, os excertos foram codificados e mesclados, tendo sido reorganizados de acordo com categorias relacionadas

1 Este artigo está relacionado à pesquisa desenvolvida durante o estágio de pós-doutoramento financiado pelo PNPD/CAPES, orientado pela Profa. Ivanilde Apoluceno de Oliveira (UEPA).

2 Tais grupos foram a metodologia utilizada durante pesquisa nacional do Observatório Nacional de Educação Especial (ONEESP), que objetivava "a avaliação em âmbito nacional do programa de implantação de Salas de Recursos Multifuncionais (SRM), promovido pela Secretaria de Educação Continuada, Alfabetização, Diversidade e Inclusão - SECADI/MEC" (OBSERVATÓRIO NACIONAL DE EDUCAÇÃO ESPECIAL, 2013). Envolveram, no estado do Pará, professores e gestores de dois municípios, num total de 56 pessoas ( 34 professores e uma gestora no primeiro município, no interior do estado; 06 técnicos e 15 professores no segundo município, a capital do estado). ao quadro de formações imaginárias de Pêcheux (PÊCHEUX; FUCHS, 1997): o lugar de onde falava (ou acreditava que falava) o locutor, sobre quem se falava (quais os interlocutores assumidos como importantes no processo inclusivo), assim como os modos como o referente "inclusão" é reatualizado na relação com as memórias da educação especial, configurando-se num acontecimento discursivo (PÊCHEUX, 2006).

Para a análise discursiva, foi importante considerar a rede de relações entre aquilo que se expressa nas políticas educacionais, como ação intencional do Estado, e os muitos formatos de ação dos professores, alunos, famílias e equipes específicas de trabalho nos microespaços escolares, ou seja, as ações concretas dos sujeitos e grupos objetos dessas políticas, tratadas como "da deficiência". Tratá-las assim implica numa recusa a resumir na expressão "educação especial" o processo histórico de sujeitos que reagiram ao estigma de deficientes e ocuparam espaços diversos, inclusive o escolar. Se, neste trabalho, a docência (e, portanto, a escola) ganha centralidade, isso se deve ao modo como as ações governamentais para a inclusão escolar se concretizaram nas duas últimas décadas, culminando na Política Nacional de Educação Especial na Perspectiva da Educação Inclusiva (BRASIL, 2010), mas nosso olhar se estende para além dos processos propriamente escolares ao analisá-la. Cabe, para dar conta da tarefa proposta, apresentar uma breve revisão da literatura sobre inclusão escolar da pessoa com deficiência e sua relação com o discurso pedagógico. 


\subsection{Política de inclusão escolar e discurso pedagógico}

Resumidamente, a Política Nacional de Educação Especial na Perspectiva da Educação Inclusiva (BRASIL, 2010) concentra no Atendimento Educacional Especializado (AEE) as tarefas de inclusão escolar do aluno com deficiência. O AEE teria como função "identificar, elaborar e organizar recursos pedagógicos e de acessibilidade que eliminem as barreiras para a plena participação dos alunos, considerando suas necessidades específicas [...]" (BRASIL, 2010, p. 21). O mesmo documento estabelece a obrigatoriedade da oferta, no contraturno, do AEE, sendo que o locus desse atendimento tende a ser a sala de recursos (GARCIA, 2013). De acordo com Santiago e Santos (2015, p. 2):

A Política Nacional de Educação Especial na Perspectiva Inclusiva (BRASIL, 2010) define que a educação especial é uma modalidade de ensino que perpassa todos os níveis, etapas e modalidades, realiza o atendimento educacional especializado, disponibiliza os recursos e serviços e orienta quanto à sua utilização no processo de ensino e aprendizagem nas turmas comuns do ensino regular).

Não transparece, nas definições legais, o embate entre concepções de inclusão que atravessam a história da educação especial, uma das matrizes da ideia de inclusão. Um enfrentamento clássico era a oposição entre inclusão total (que se propunha a superar o assistencialismo das instituições privadas na educação especial) e inclusão processual (em que as contribuições de tais instituições iriam, aos poucos, sendo substituídas pela iniciativa governamental). Nessa segunda concepção, fica subentendida a destinação de verbas estatais a setores assistenciais de cunho privado, associada à incorporação de uma forte tradição médico-clínica, a qual considera a deficiência uma tragédia pessoal e centra sua intervenção na limitação, produzindo um sujeito socialmente diminuído. Fazia todo sentido, numa lógica de diminuição das atribuições do Estado, que este se amparasse na iniciativa privada para o suporte à educação da pessoa com deficiência, sob a argumentação de que esse setor já teria know-how suficiente para tanto, baseado no histórico de assistencialismo do Estado brasileiro. Também é preciso levar em conta que a assistência se am- para em pressupostos diferentes e muitas vezes contraditórios àqueles propriamente educacionais.

É por isso que, no embate contra essa tradição médico-clínica, uma concepção social da deficiência fortalece-se pouco a pouco, oriunda das ciências sociais aplicadas. Do ponto de vista dessa concepção, o potencial das pessoas, sua capacidade de organização e de intervenção deveriam ser o foco das políticas educacionais para a deficiência, produzindo, coletivamente, uma compensação das limitações impostas pelo preconceito e pelo estigma. Desse modo, deficiência é entendida como produção da cultura, e não como produção da lesão no corpo (DINIZ, 2007; DINIZ; BARBOSA, 2013; MENDES; PICCOLO, 2013). Para a educação, essa concepção vem ancorar-se numa visão crítica, que não perde de vista a história de marginalização da escola pública brasileira. As políticas atuais, tendo a escola como centro do atendimento especializado, tendem ainda a ignorar tal história de marginalização vivida por essa mesma escola, a qual não tem como se isolar dos conceitos e preconceitos próprios da sociedade de que faz parte. Não sendo o espaço idealizado onde enfim serão superados os séculos de isolamento e as barreiras impostas às pessoas com deficiência e tendo mais a aprender com elas e suas lutas do que propriamente a ensinar, a escola se configura como uma "arena discursiva" onde as disputas se travam, e é nesse sentido que ela nos interessa como pesquisadores.

Não entraremos aqui nos detalhes desse processo, mas é possível lembrar pesquisas recentes, as quais têm apontado como limites dessas políticas o excesso de atribuições do professor (BAPTISTA, 2013; GARCIA, 2013), concepções de deficiência ligadas a características individuais (DINIZ; BARBOSA, 2013; SILVEIRA; ENUMO; ROSA, 2012), a ênfase no atendimento individualizado (GARCIA, 2013), a reprodução da marginalização dos sujeitos e grupos marcados com o estigma de especial (seja o próprio aluno, seja o professor, seja a turma, seja o processo formativo) expressa nas histórias de vida de tais sujeitos (CAIADO, 2006; GLAT, 1989; GLAT; PLETSCH, 2009), a patologização da educação especial (NABUCO, 2010), entre outras.

A variedade de trabalhos acerca das políticas de inclusão, no Brasil, contrasta com a pouca pro- 
dução sobre as relações entre discurso pedagógico e inclusão. Em uma análise acerca das relações entre fracasso escolar e discurso pedagógico, Paula e Tfouni (2009, p. 124) apontam as assimetrias próprias do mundo da instituição escolar como componentes do discurso pedagógico:

[...] o discurso pedagógico escolar (DPE), no lugar privilegiado do saber estabelecido, retroage sobre o que ele se propõe explicar (a educação, a aprendizagem, a escola etc.) posicionando os sujeitos (alunos e professores, funcionários) no lugar de meros receptores/ transmissores de conhecimentos institucionalizados, em uma lógica que favorece o fracasso escolar.

Em Giorgenon e Romão (2013, p. 273, grifo do autor), numa discussão sobre a tendência ao autoritarismo no discurso pedagógico e sua consequente recusa à heterogeneidade, temos que:

[...] o discurso da inclusão, embora abra as portas da escola regular para alunos considerados fora dos padrões de normalidade, não tem incluído a singularidade de cada sujeito, seja ele nomeado como com ou sem deficiência. Temos trabalhado, desde então, com a hipótese de que, atravessado pelo discurso pedagógico que tende ao autoritário (ORLANDI, 2003) e à homogeneização dos indivíduos e das práticas, o discurso da inclusão ganha voz apenas na massificação, em dizeres de 'socialização', na colocação de alunos para dentro da escola, sem, no entanto, haver lugar para a inclusão do heterogêneo.

Temos então, nesses autores, que o próprio modo como a escola se estrutura trabalha contra a perspectiva da aceitação do diferente; desse modo, não tratar das assimetrias e atribuir à escola a tarefa da inclusão parece um contrassenso. Essa questão, pouco tratada nas pesquisas sobre inclusão, justifica o interesse em analisar o funcionamento do discurso pedagógico em torno da temática da inclusão da pessoa com deficiência na escola.

\section{Pressupostos teórico-metodológicos}

Para tratar da questão do funcionamento do discurso pedagógico em torno da inclusão da pessoa com deficiência na escola, necessitamos antes assumir alguns pressupostos. $O$ primeiro, de que o discurso é produção cultural e coletiva, não sendo entendido como se fosse gerado unicamente pela consciência do sujeito falante. Assim, fala-se aquilo que é possível falar, numa dada época, numa dada conjuntura. O segundo pressuposto é que, ao falar o que é possível falar, o fazemos de uma dada maneira, entre as muitas possibilidades dadas pela língua. No entanto, o fazemos como se fôssemos autores daquilo que falamos e como se fosse nossa a escolha do modo como dizemos. Pêcheux chama isso do duplo esquecimento: esquecemos que a ideologia perpassa a linguagem, de forma que o dito é atravessado por não-ditos, e esquecemos que os modos de enunciar produzem certos efeitos de sentido e não outros:

Concordamos em chamar esquecimento $n^{\circ} 2$ ao 'esquecimento' pelo qual todo sujeito falante 'seleciona' no interior da formação discursiva que o domina, isto é, no sistema de enunciados, formas e sequências que nela se encontram em relação de paráfrase um enunciado, forma ou seqüência, e não um outro, que, no entanto, está no campo daquilo que poderia reformulá-lo na formação discursiva considerada.[...] Por outro lado, apelamos para a noção de 'sistema inconsciente' para caracterizar um outro 'esquecimento', o esquecimento $n^{\circ} 1$, que dá conta do fato de que o sujeito-falante não pode, por definição, se encontrar no exterior da formação discursiva que o domina. (PECHÊUX, 1997, p. 173, grifo do autor).

Dizemos, também, para uma plateia invisível, submetidos às coerções socioculturais que o olhar dessa plateia impõe à nossa sensibilidade (podemos nos submeter mais ou menos a essas coerções, reagir a elas, mas não as ignorar). Recorremos à fase inicial de Pêcheux (PÊCHEUX; FUCHS, 1997), chamada de AD-1, para analisar o processo discursivo como um jogo de efeitos de sentido, ancorado em formações imaginárias. Segundo Orlandi (2005b, p. 11, grifo do autor), "Pêcheux pensa o sentido como sendo regulado no tempo e espaço da prática humana de-centralizando o conceito de subjetividade e limitando a autonomia do objeto linguístico". A produção dos sentidos se faz nos enfrentamentos históricos, pressupondo sempre uma formação imaginária. Pêcheux (PÊCHEUX; FUCHS, 1997, p. 83) organizou, conforme o Quadro 1, as formações imaginárias existentes, segundo ele, em qualquer processo discursivo. 
Quadro 1 - Quadro das formações imaginárias, segundo Pêcheux

\begin{tabular}{|l|l|l|}
\hline $\begin{array}{l}\text { Expressão que } \\
\text { designa as formações } \\
\text { imaginárias }\end{array}$ & $\begin{array}{l}\text { Significação da } \\
\text { expressão }\end{array}$ & $\begin{array}{l}\text { Questão implícita cuja “resposta" subentende } \\
\text { a formação imaginária correspondente }\end{array}$ \\
\hline IA(A) & $\begin{array}{l}\text { Imagem do lugar } \\
\text { de A para o sujeito } \\
\text { colocado em A }\end{array}$ & “Quem sou eu para lhe falar assim?" \\
\hline IA(B) & $\begin{array}{l}\text { Imagem do lugar } \\
\text { de B para o sujeito } \\
\text { colocado em A }\end{array}$ & “Quem é ele para que eu lhe fale assim?" \\
\hline IB(B) & $\begin{array}{l}\text { Imagem do lugar } \\
\text { de B para o sujeito } \\
\text { colocado em B }\end{array}$ & “Quem sou eu para que ele me fale assim?" \\
\hline IB(A) & $\begin{array}{l}\text { Imagem do lugar } \\
\text { de A para o sujeito } \\
\text { colocado em B }\end{array}$ & “Quem é ele para que me fale assim?" \\
\hline
\end{tabular}

Fonte: Pêcheux e Fuchs (1997, p. 83).

Esse esquema se referia ao "lugar" ou "posição" social onde quem fala acha que se situa e acha que o outro se situa, assim como uma antecipação daquilo que o outro pensa acerca do próprio lugar e do lugar do interlocutor. Pêcheux (PÊCHEUX; FUCHS, 1997) complementa o quadro afirmando que o referente (entendido como o contexto) também faz parte das condições de produção do discurso, de tal forma que as antecipações discursivas precisam levar em conta todas as informações e posicionamentos acerca da situação na qual os sentidos são produzidos. Nessa primeira fase de sua produção, Pêcheux (PÊCHEUX; FUCHS, 1997, p. 311-312) pressupunha que um "sujeito-estrutura determina os sujeitos como produtores de seus discursos num espaço discursivo supostamente dominado por condições de produção estáveis e homogêneas". Desse modo, pouca variação haveria nesse processo imaginário, preso aos lugares previstos na estrutura social.

Avançando, numa segunda fase (AD-2), para uma compreensão das "relações de força desiguais entre processos discursivos" (PÊCHEUX; FUCHS, 1997, p. 341), o autor retomou "a noção de formação discursiva tomada de empréstimo a Michel Foucault" (PÊCHEUX; FUCHS, 1997, p. 314), relacionando-a à ideologia:
As palavras, expressões, proposições, etc. mudam de sentido segundo as posições sustentadas por aqueles que as empregam, o que quer dizer que elas adquirem seu sentido em referência a essas posições, isto é, em referência às formações ideológicas [...] nas quais essas posições se inscrevem. Chamaremos, então, formação discursiva aquilo que, numa formação ideológica dada, isto é, a partir de uma posição dada numa conjuntura dada, determinada pelo estado da luta de classes, determina o que pode e deve ser dito (articulado sob a forma de uma arenga, de um sermão, de um panfleto, de uma exposição, de um programa etc.). (PÊCHEUX; FUCHS, 1997, p. 160, grifo do autor).

Desse ponto de vista, os indivíduos não dizem o que querem, por estarem inseridos na cultura e na história, atravessadas pelos enfrentamentos de classe. São “[...] 'interpelados' em sujeitos-falantes (em sujeitos de seu discurso) pelas formações discursivas que representam 'na linguagem' as formações ideológicas que lhes são correspondentes" (PÊCHEUX, 1997, p. 161). A noção de interdiscurso é acrescentada

[...] para designar 'o exterior específico' de uma FD [formação discursiva] enquanto este irrompe nesta FD para constituí-la em lugar de evidência discursiva, submetida à lei da repetição estrutural fechada: o fechamento da maquinaria é, pois, conservado, ao 
mesmo tempo em que é concebido então como o resultado paradoxal da irrupção de um 'além' exterior e anterior. (PÊCHEUX, 1997, p. 314).

Irrompendo na formação discursiva, é o interdiscurso (ideologia hegemônica) que lhe dá sentido, não sendo possível ainda pressupor que, pelo próprio modo de funcionar do discurso, deslizamentos de sentido possam produzir formações discursivas que escapem ao estabelecido. O duplo esquecimento a que se referia Pêcheux (PÊCHEUX; FUCHS, 1997) (de que o que é dito poderia ser dito de outro modo, e de que o discurso não tem origem no sujeito) imprimiria à formação discursiva sua coerência, ocultando os processos de assujeitamento.

Em sua última fase (AD-3), Pêcheux (2006, p. 49) assume outra "posição de trabalho" e admite que as formações ideológicas não podem escapar aos equívocos que são próprios da língua, nem aos modos de acontecer do discurso, afetadas pelo ordinário da vida. Assume a existência de "relação entre os universos logicamente estabilizados e o das formulações irremediavelmente equívocas" (ORLANDI, 2006, p. 8) Tomamos aqui as leituras sobre o lugar de quem fala e de quem é falado como parte da estrutura do discurso, logicamente estabilizada: tais lugares não são dados pelo desejo de quem fala, e sim pelo pertencimento ideológico. No entanto, não evitamos as oscilações da descrição desses lugares como efeito do acontecimento: no descrever da experiência particular do processo inclusivo, o falante o reinterpreta; no reinterpretar, retoma sentidos que podem escapar à lógica do que "pode e deve ser dito" (PÊCHEUX; FUCHS, 1997, p. 160). O autor questiona a própria noção de formação discursiva (PÊCHEUX; FUCHS, 1997, p. 315), de modo que "o que pode e deve ser dito" já não é estabelecido apenas de fora e de acima (de um interdiscurso fechado), mas também nas relações com alteridades outras, em negociações menos assimétricas, no interior da própria formação discursiva. As formações discursivas seriam, então, heterogêneas por definição, como apontam Authier-Revuz (1990) e Maingueneau (1997), ao formularem a noção de heterogeneidade constitutiva.

A nova posição de trabalho de Pêcheux, anunciada acima, implica em aproximar "as práticas da 'análise da linguagem ordinária' [...] e as práticas de 'leitura' de arranjos discursivo-textuais"
(PÊCHEUX, 2006, p. 49). Segundo Orlandi (2006, p. 9), Pêcheux "aceita seu desafio entrecruzando três caminhos: o do acontecimento, o da estrutura e o da tensão entre descrição e interpretação na Análise de Discurso". Entendendo que a produção discursiva não pode evitar a tensão entre estrutura e acontecimento, Pêcheux aponta que, além dos sentidos estabilizados nas formações discursivas e ideológicas, também é possível encontrar as contradições, o equívoco, o discurso "em produção". Trabalha com a língua, "não apenas como sistema e no seu funcionamento, mas também naquilo que ela tem de singular: o equívoco, o implícito, a falta, a falha, o silêncio" (CESÁRIO; ALMEIDA, 2010, p. 5). O acontecimento, então, pode ser definido como "ponto de encontro entre uma atualidade e uma memória" (PÊCHEUX, 2006, p. 17), num confronto discursivo em que as muitas forças disputam sua descrição. O encontro entre interdiscurso (pensado como ideologia) e formação discursiva se dá aí, e se materializa de uma dada forma, numa dada prática, que codetermina tal formação.

Analisar falas de professores em grupos focais levando em conta as proposições acima implica, em nossa opinião, considerar as questões de poder imbricadas (que têm relação com as forças hegemônicas, mas também com aquelas que disputam espaço nas definições dos processos): que "lugares" podem ser pressupostos nas falas daqueles que se dispõem a falar sobre as salas de recursos? Quais as condições de produção do discurso onde tais falas se inscrevem (que coerções agem sobre ele no presente, que história tem a produção discursiva que lhe dá suporte)? Como as falas produzidas neste momento histórico, em que se encontram "uma atualidade e uma memória" (PÊCHEUX, 2006, p. 17), deslocam essas condições, produzindo efeitos de sentido para além do esperado, do já dito? Que silenciamentos pode-se pressupor a partir de tais falas? Essas perguntas levaram à elaboração de um dispositivo analítico usado no tratamento das falas, primeiramente entendendo-as como parte de um "discurso pedagógico", ou seja, como uma produção que não se elabora na subjetividade de cada professor (a) falante, mas nas elaborações, ao longo da história, que estabelecem o que deve/pode falar um(a) professor(a): no interdiscurso. No caso em pauta, o que pode/deve falar um(a) professor(a) 
cuja atuação se inscreve no campo discursivo denominado educação inclusiva. Em segundo lugar, ao enfocar as descrições e análises do processo inclusivo como acontecimento discursivo, levamos em conta os confrontos mais imediatos, presentes na prática discursiva em sua heterogeneidade.

Assumindo o duplo esquecimento proposto por Pêcheux na segunda fase da AD, Orlandi (2003, p. 15) considera a existência de dois processos "constitutivos da tensão que produz o texto" (o polissêmico e o parafrástico). A polissemia se refere às múltiplas possibilidades de sentido produzidas na relação entre referente e prática discursiva; a paráfrase, à multiplicidade de modos de dizer a mesma coisa, cada modo afetando os sentidos. A autora categoriza os discursos com base na "relação entre os interlocutores e o referente, isto é, nas suas condições de produção" (ORLANDI, 2003, p. 29), e considerando isso estabelece a existência de discursos lúdicos, polêmicos e autoritários.

No discurso lúdico há a expansão da polissemia, pois o referente do discurso está exposto à presença dos interlocutores; no polêmico, a polissemia é controlada, uma vez que os interlocutores procuram direcionar, cada um por si, o referente do discurso; e, finalmente, no discurso autoritário há a contenção da polissemia, já que o agente do discurso se pretende único e oculta o referente pelo dizer.

Para Orlandi (2003, p. 31-32), o discurso pedagógico tende a conter as características do discurso autoritário; o professor é o principal agente do discurso e os sentidos se estabelecem a partir do mundo da ciência. A possibilidade de "encaminhar uma posição crítica diante dessa caracterização do DP" seria transformá-lo em um discurso polêmico, interferindo criticamente no processo de constituição de sentidos. "Especificamente, em relação ao DP, uma forma não autoritária é explicitar o jogo de efeitos de sentido [...]". Ainda que o discurso pedagógico possa disputar, de forma polêmica, os significados da referente "inclusão", suas características mais fortes vêm do discurso autoritário: nele, há pouca reversibilidade entre os interlocutores (quem pode dizer a respeito da inclusão escolar é o especialista; cabe aos outros ouvir e aprender), e há um controle da polissemia estabelecido pelos manuais do que significa ser inclusivo. Diz Orlandi (2003, p. 29-30):
O DP [discurso pedagógico] se dissimula como transmissor de informação, e faz isso caracterizando essa informação sob a rubrica da cientificidade. O estabelecimento da cientificidade é observado [...] em dois aspectos do DP: a meta-linguagem e a apropriação do cientista feita pelo professor. O problema da meta-linguagem se funda no tratamento do referente, isto é, conhecimento do fato fica subsumido, no DP, pelo conhecimento de uma certa metalinguagem: fixam-se as definições e excluem-se os fatos. O referente é um referente discursivo: são conceitos elaborados naquele ou em outros discursos, enunciados implícitos.

Tomando essa noção de discurso pedagógico para analisar as falas de professores, entendemos tais falas como produzidas em coletividade, e apenas nela ganhando sentido, organizadas pelas relações de poder vigentes e pelas reações a elas. Não são tidos como produção particular e inconfundível do sujeito. Os sentidos "[...] são determinados pela maneira como nos inscrevemos na língua e na história e é por isto que significam e não pela nossa vontade" (ORLANDI, 2005a, p. 35). A memória do "lugar de docente" na história (um já-dito), permeada por tais relações, atravessa os ditos e insinua não-ditos. Enquanto acontecimento discursivo, o narrar do processo denominado inclusivo se organiza como um ponto de encontro entre atualidade e memória (PÊCHEUX, 2006): os lugares do docente de AEE e da sala comum se ancoram em pré-construídos, dados previamente no "real" do discurso pedagógico, mas também são produzidos no batimento entre interpretação e descrição do momento presente: não há como descrever a inclusão da pessoa com deficiência sem interpretá-la.

\section{Resultados e conclusões}

Entendendo o processo discursivo como jogos de sentido cuja regulação precisa ser buscada nas dinâmicas culturais e históricas, analisamos as discussões dos grupos focais, após transcritas, destacando como marcas discursivas aquelas que evidenciavam imagens elaboradas pelo falante com relação a dois aspectos: a) ao lugar que ele próprio pensava ocupar no processo de inclusão (a seguir denominados "os lugares de onde se fala"), 
implicando numa busca de resposta às perguntas pecheutianas "Quem sou eu para lhe falar assim?" e "Quem sou eu para que ele me fale assim?"; b) Aos interlocutores que ganham lugar no interior do diálogo e o lugar que ocupam no imaginário do locutor ("de quem se fala", no texto a seguir, respondendo às questões "Quem é ele para que eu lhe fale assim?" e "Quem é ele para que eu the fale assim?").

Analisamos, portanto, os lugares sociais explícitos ou implícitos no texto, considerando que, num grupo focal, a conversa implica em compromissos de sentido. Mobiliza-se, nelas, o dito aceitável e socialmente situado; as memórias que ganham lugar em tais trocas não são aleatórias: são evocadas justamente pelo seu pertencimento à rede de sentido em funcionamento. Por fim, também foram destacados como marcas os equívocos, o não dito, os silenciamentos, justamente por considerar que o discurso "em produção" numa conversa (o discurso em acontecimento) pode evidenciar aquilo que se contrapõe ao que é aceito como verdadeiro, conformando-se como arena de disputas. No próprio empenho de autodefinição, o processo de escolarização que se deseja (e se descreve como) inclusivo precisa borrar tais conflitos, de modo a parecer internamente coerente.

\subsection{Os lugares de onde se fala}

Para poder falar de "lugares", "posições discursivas", precisamos refletir acerca do funcionamento de um grupo focal. Em teoria, os membros do grupo se colocam em lugares simétricos: fala-se em pé de igualdade, livremente, em torno da temática proposta pelos pesquisadores. Então precisamos partir de duas premissas: a) de que a temática é proposta a priori (interessa saber disso, e não daquilo; no caso, interessa saber como é avaliado o aluno, o processo formativo por que passa o professor e como é o funcionamento do atendimento especializado); b) de que as posições ocupadas de fato no mundo pedagógico (especialista, docente de sala de recursos, docente de sala comum) e as assimetrias de poder envolvidas afetam as posições imaginárias. Colocando-nos como analistas de discurso, assumimos que tanto a igualdade e a liberdade de falar o que se quer são ilusórias, quanto é vã a expectativa de que o grupo se atenha a falar apenas daquilo que lhe é proposto. De acordo com a formação imaginária acerca da posição em que se coloca o falante (e das oscilações dessa posição), variam os modos de operar no discurso. Os indícios desse lugar oscilante, entre o dito, o silenciado e o insinuado, vão se elaborando na produção discursiva. Assim, às vezes a voz vem do lugar do especialista, mas mesmo a noção de especialização vai sofrendo deslizamentos de sentido, como se pode ver em E2 e E3:

[...] no caso, quando a gente faz uma especialização direcionada a Educação Especial, quando a gente chegar na prática, aquela especialização a gente vê que não suporta o que a gente vai atender realmente. (E2, grifo nosso).

[...] eu pedi para ele colocar nessa especialização... de práticas pedagógicas para trabalhar com alunos especiais. São muitas deficiências, são, mas coloque para cada uma deficiência, como atender esse aluno. Agora assim, claro, onde é que eu vou arrumar esse professor que tem a teoria e a prática? Realmente há uma carência, eu percebo que há uma carência [...] eu creio que as especializações hoje ainda não garantem essa... eu vou fazer uma especialização em Ed. Especial e tu vais sair apta para atender um autista? Não. (E3, grifo nosso).

A noção de especialista, como foi dito, desliza em seus sentidos, sendo redesenhada nas falas. No dicionário Aulete Digital (2017), "especialista" quer dizer "que se especializou em determinado assunto ou atividade; que tem profundo conhecimento do que faz". No atendimento especializado, no entanto, cada deficiência, transtorno ou alta habilidade requereria um curso de especialização; não há curso que dê conta da diversidade de situações que o professor encontrará na sala de recursos - "aquela especialização a gente vê que não suporta o que a gente vai atender realmente" (E2). Não se espera que tais cursos formem um especialista em educação, mas em educação de autistas, de surdos, de cegos etc. Resta um incômodo subjacente, um não-dito que se poderia resumir nas seguintes questões: o fazer docente relacionado à deficiência deveria reproduzir o nível de especialização do psicólogo, do neurologista, do psiquiatra? Não seria contraditório com a própria 
noção de especialização querer reunir todos esses saberes na formação de um único profissional (o professor de sala de recursos)? Na crítica presente em E3, subjaz a esperança de que isso venha a ser possível, expressa nas marcas discursivas "hoje" e "ainda", na penúltima linha ("as especializações hoje ainda não garantem...”).

No excerto E66, a busca por saber se desloca da especialização para o fazer cotidiano, para a experiência da mãe, dos colegas de trabalho:

Quando eu deparei pela primeira vez aqui com um aluno autista, autista hiperativo... e a minha colega que atendia. [...] Eu fiquei olhando. Ele detonou a sala inteira. Porque ele passava, pegava uma coisa, pegava outra... Ai eu fiquei parada. Eu disse: 'Gente!' Ai eu pensei: 'No momento em que ela não estiver, que eu for atendê-lo, como será? $O$ que eu vou fazer?' $E$ aí eu fui verificar as várias possibilidades. Ai eu fui trocar com ela [a colega]: como eu faço? Eu fui conversar também com a mãe. E eu fui buscar com ela direcionamento de como atender essa criança no momento em que ela não estivesse o que eu deveria fazer? Como buscar essas informações? Como buscar fundamentos? Porque ele andava tanto e ela mostrava alguma coisa e ele vinha. Depois ela disse: 'Tu vai ver que no processo ele nem vai passar um tempo'. E chegou mesmo nessa adaptação nossa... (E66, grifo nosso).

Em E66, o lugar de especialista, posição de status, vai sendo abandonado em razão da produção de um saber cotidiano, buscado na figura da colega ("aí eu fui trocar com ela: como eu faço?") e da mãe da criança ("eu fui conversar também com a mãe"). O fio do discurso, entendido por Pêcheux (PÊCHEUX; FUCHS, 1997, p 166) como "o funcionamento do discurso com relação a si mesmo (o que eu digo agora, com relação ao que eu disse antes e ao que direi depois; portanto, o conjunto dos fenômenos de co-referência que garantem aquilo que se pode chamar o 'fio do discurso')" se esgarça, porque a crença na especialização não se sustenta. Não se sustentando, esse fio dá nós: impossibilitado de manter a rede de sentidos própria do lugar do especialista, o movimento discursivo se desloca para um lugar de menor coerção social com relação ao falante: é nas relações com colegas e família que ele busca "direcionamento de como atender essa criança".

\subsection{Sobre quem se fala: a produção de um lugar para o outro}

A posição que o outro ocupa nos enunciados diz bastante sobre a formação discursiva em funcionamento. No quadro sobre as formações imaginárias criado por Pêcheux (PÊCHEUX; FUCHS, 1997, p. 83), isso é expresso como a "imagem do lugar de B para o sujeito colocado em A" ("Quem é ele para que eu lhe fale assim?"). Esse lugar do outro organiza o lugar em que o falante coloca a si mesmo, na ilusão de "dono" do próprio discurso.

Não há fronteira ou solução de continuidade "no interior" de uma formação discursiva, de modo que o acesso ao "não dito" como "dito de outro modo" (aceito ou rejeitado) permanece constitutivamente aberto. Por outro lado, essa interpretação nos permitia dar conta da impressão de realidade de seu pensamento para o sujeito-falante ("eu sei o que estou dizendo", "eu sei do que estou falando"), impressão deflagrada pela abertura constitutiva da qual esse sujeito se utiliza constantemente através do retorno sobre si do fio de seu discurso, da antecipação de seu efeito e da consideração da discrepância introduzida nesse discurso pelo discurso de um outro "[...] para explicitar e se explicitar a si mesmo o que diz e 'aprofundar o que ele pensa"'. (PÊCHEUX, 1997, p. 173-174).

No discurso, é produzido um lugar dos falantes como porta-vozes do movimento inclusivo, assumindo-se como especialistas. Desse lugar, produzem discursivamente o lugar do outro professor (o qual atua na sala comum) como aquele que produz situações de exclusão. Podemos acompanhar essa dinâmica em E138: uma história é contada e, na interpretação do locutor, a voz do outro é modulada em três movimentos: no primeiro, é o próprio locutor que acha ("acho que na concepção dela ele não era capaz de perceber"); no segundo, invoca pelo discurso indireto um segundo locutor, atribuindo-lhe aquele ponto de vista ("ela achou que ele não tinha a capacidade"); e no terceiro, o outro entra diretamente no diálogo, pela afirmação de um dito, e já não é mais singular, incorpora outros ditos enquadrados no mesmo ponto de vista a ser combatido ("Elas dizem que sim [que o que elas fazem é inclusivo]"). 
Vou dar um exemplo, nós temos um aluno que é down, ele é superinteligente, a mãe dele contando assim, numa escola a professora fez as fitinhas com o nome de todos os alunos e a professora não fez o nome dele, acho que na concepção dela ele não era capaz de perceber que todos receberam o cracházinho, o peixinho com o nome, menos ele. 'Tia, cadê o meu? Meu nome, tia? Cadê o meu nome?', e ela se sentiu naquilo ali, recolheu o nome de todos os alunos e no dia seguinte ela levou a fichinha com o nome dele, quer dizer, isso foi uma exclusão, porque ela achou que ele não tinha a capacidade. No ensino inclusivo? Não. Elas dizem que sim, mas na nossa concepção, não. (E138, grifo nosso).

Ao dizer o que pensa o outro, atribuindo-lhe determinado lugar, o falante também fala do lugar que atribui a si mesmo, que em E21 e E132 é desenhado como o lugar do esclarecimento, daquele que já percebeu a verdade (teve uma visão e precisa passar adiante, no primeiro excerto, e toma a dianteira da professora "sem esclarecimento", no segundo).

Eu estou aqui, na verdade, há dois anos na educação especial, por conta dessa necessidade que eu tinha antes de tentar proporcionar também aos meus colegas essa visão do que é a educação especial, o que é trabalhar com o diferente, do que é estar ali com o outro. E eu sou muito agraciada e sou muito feliz. (E21, grifo nosso).

Nós temos um aluno na nossa sala que ele tem dezessete anos. Quando ele iniciou na sala multifuncional, a outra [a professora da sala comum] dizia assim: 'Ah, ele não consegue fazer isso'. Na hora do lanche ela pegava o dele e ia comprar. Eu digo:

'Ele tem capacidade de comprar o lanche dele, você vai lá ao portão comprar o seu lanche'. E ele foi lá e comprou o lanche. Daquele dia em diante ele foi sempre comprar o lanche dele. (E132, grifo nosso).

Em E21, o falante atribuía a si uma percepção antecipada, com relação aos demais colegas, do que seria a educação especial (provavelmente tomada como sinônimo de inclusão), incorporando a tarefa (missionária?) de disseminar essa visão entre os colegas. Em E132, a heterogeneidade é marcada pelo discurso direto: “a outra dizia assim: 'Ah!, ele não consegue fazer isso ", assim como pela negação da nominação à colega ("a outra"), a qual não percebe as capacidades do aluno com deficiência e precisa da intervenção direta.
No excerto a seguir, produzem-se lugares para outro "outro": o aluno em situação de deficiência.

[...] a gente viu que não era bem assim, que aquele aluno não era assim tão comprometido, então optamos por retê-lo para trabalharmos melhor com esse aluno, dar mais uma chance para passar mais tempo com ele. Ele conseguiu até aprender a ler $\boldsymbol{e}$ escrever, depois a gente botou ele para a frente, no caso $6^{\circ}$ ano. Fizemos isso para trabalharmos melhor com ele, dar uma chance para ver se ele desenvolvia. (E136, grifo nosso).

Nos excertos em análise, outros efeitos de sentido são produzidos em torno das possibilidades de desenvolvimento do aluno. As explicações acerca de retenção (manter o aluno no mesmo ano do curso) se articulam com as limitações do aluno. A aprendizagem ("ele conseguiu até aprender a ler e escrever") é descrita de modo separado dos avanços ("e depois a gente botou ele para a frente"), atribuídos ao falante e outros na mesma posição que ele ("a gente"). O "até" na primeira frase implica que a aprendizagem foi além do esperado, evidenciando a posição em que o outro é colocado no enunciado. O lugar de quem está autorizado a "dar mais uma chance" é distinto daqueles a quem a chance é dada. $O$ discurso pedagógico autoritário aqui é evidente, no sentido que lhe atribui Orlandi (2003): não há expectativa de reversibilidade na relação entre aquele que fala e aquele que é falado, a polissemia é contida, já que os sentidos de "aprender" e "avançar" são estabelecidos por quem fala e não por quem é falado.

O processo discursivo é tomado, nesta análise do discurso pedagógico, como a imbricação de jogos de sentido regulados cultural e historicamente. As relações entre interlocutores e referente dentro do discurso pedagógico são explicitadas na medida em que são destacados os lugares de onde falam aqueles que descrevem as salas de recursos e o lugar do outro em tais descrições. Quando o lugar de quem fala se situa no âmbito da especialização, o lugar do outro (daquele que é falado) incorpora o despreparo, o preconceito, a fragilidade. Quando se desloca o lugar de quem fala para o campo da formação inadequada (daquele que não sabe), o lugar de quem é falado se modifica: a relação entre professor de AEE e professor de sala comum aí ganha foros de 
parceria. O discurso pedagógico, que apresenta certa irreversibilidade própria do discurso autoritário, é aqui afetado pela insegurança dos falantes com relação aos próprios lugares de enunciação.

\subsection{0 discurso como acontecimento}

Os lugares de onde se fala, as antecipações do discurso do outro (de quem se fala) e as formações discursivas resultantes têm relação com as condições de produção do discurso, entendidas como coerções que agem sobre tal discurso em seu processo de elaboração, tanto do ponto de vista imediato quanto histórico e projetivo. Fala-se de uma posição (imediata), ancorada em dada memória, pressionada pelo enfrentamento entre os projetos de sociedade e de homem em disputa. Tomando o discurso como acontecimento, levamos em conta o sistema e seu funcionamento, suas regularidades, mas também as singularidades do acontecer, destacando aquilo que deixa de ser dito ou que é dito de modo implícito ou equívoco.

Enquanto acontecimento, o discurso sobre a política de educação inclusiva nas falas analisadas se apresenta de modo equívoco em vários momentos. O fazer discursivo é descrito, seguido de uma retomada em que aquela descrição é negada. O real que deve ou deveria ser, numa suposta falha no fio que organiza a enunciação, é cotejado com o real que está acontecendo, e isso gera elaborações que poderíamos resumir com a expressão "é, mas não é”, a qual interpretamos como o acontecimento da prática pedagógica em suas contradições. As condições de produção do discurso apresentam tensões que se organizam discursivamente nos excertos apresentados a seguir.

É claro que a gente não deixa de atender o aluno por causa de um laudo. Se a gente identifica que o aluno tem uma suspeita de alguma deficiência, ele fica sendo atendido até esse laudo aparecer. $\boldsymbol{E}^{-}$ claro que às vezes nunca aparece, não é? Porque o neurologista é muito difícil. De mais, então demora cerca de um ano, dois anos, três anos, e esse aluno fica ali sendo atendido, mas como suspeita da deficiência. (E30, grifo nosso).

Acontece assim também... o aluno chega na escola já levando o laudo na secretaria. Nesse caso? Grande parte não tem laudo. Grande parte dos nossos alunos não tem laudo. Outros têm, já levam e já é feita logo [...] Tem essa situação. (E93, grifo nosso).

Até por que a gente tem feito um trabalho na rede que a gente faz a matrícula da pessoa com deficiência antes da matricula dos demais alunos para facilitar a enturmação desse aluno. Desse estudante. E nesse tempo todo, a gente conversa com a família, com a comunidade escolar, de maneira que quando ela vem fazer a matricula, ela já traz a informação. (E94, grifo nosso).

Em E30, primeiro, não é exigido o laudo. $\mathrm{Ne}$ entanto, sem o laudo o aluno fica na condição de "suspeito" de deficiência. Em E93, a matrícula de quem tem o laudo "já é feita logo", o que levaria a crer que a matricula de quem não tem laudo demora mais. Ocorre um movimento pendular entre a descrição de uma idealização (o correto seria garantir a matrícula escolar, independentemente de laudo), baseada nas prescrições legais ou no desejo militante, e o que de fato acontece: não se pode evitar o real "em acontecimento". Esse lugar privilegiado do laudo médico nas decisões pedagógicas aponta para uma subalternização do discurso pedagógico com relação ao discurso médico. O limbo em que ficam as crianças "com suspeita" de deficiência (em E30) não é menos estigmatizante do que o lugar social daqueles já diagnosticados (os que têm laudo, levam no ato da matrícula e têm esta agilizada, em E93). No discurso, ganha mais importância o laudo do que as possibilidades pedagógicas.

A descrição formal da função do AEE, que se materializa na sala de recursos, seria "identificar, elaborar e organizar recursos pedagógicos e de acessibilidade que eliminem as barreiras para a plena participação dos alunos, considerando suas necessidades específicas [...]" (BRASIL, 2010, p. 21). Tal definição não coincide com a experiência vivida pelo enunciador, tanto no excerto anterior quanto presente no excerto E109, mas é como se sua experiência não afetasse a descrição.

[...] Tem sala de recurso aqui no Centro. [...] Tem crianças que as meninas já começaram a fazer avaliação. Tem característica de sala de recurso só que não tem nem como encaixar, porque a sala está lotada [...] Então, tem que esperar sair alguma criança, tem que esperar... Como é que faz? O pai está deixando de levar? A criança mudou de escola? Então vai, chama. Desocupou uma vaga, abriu vaga, 
vai, chama a USE e manda. Fora esse processo tem ainda o estatuto da família que [...] não leva. Chegar na escola, ela precisa de transporte. A família não tem nem o que comer, imagina o dinheiro de ônibus para trazer toda semana aquela criança para atendimento. Paga o responsável, paga a criança, às vezes são duas passagens de ônibus para vir e duas para voltar, então tem muito essas questões. (E109, grifo nosso).

As condições de pobreza a que a família é submetida, a superlotação da sala, em E109, aparecem como questões estranhas à definição da sala de recursos. O verbo "encaixar" nos remete a esse desencontro: a criança deveria estar na sala de recursos, que foi criada para atender às suas condições (conforme as determinações legais), mas as condições reais não permitem tal "encaixe". Encaixe, no dicionário, é definido como a "união ou juntura de duas peças, talhadas de forma tal que uma, saliente, penetre numa fenda aberta na outra, ajustando-se ambas perfeitamente" (DICIO, 2015). A peça "que não pode ser encaixada", no caso, é a criança. Numa paráfrase, poderíamos inverter a ordem, mostrando como aquela sala não se encaixa na descrição legal de "sala de recursos"; esse exercício discursivo deslocaria o status de problema da criança para a sala de recursos, produzindo outro movimento interpretativo. O encaminhamento para atendimento clínico é descrito num movimento semelhante (de obrigação legal, se transforma em sugestão); a reiteração do verbo "sugerir" indica, em E104, o esforço do falante em situar seu lugar pedagógico dentro das normativas:

Se nós tivéssemos parcerias institucionalizadas seria muito melhor, porque, digamos assim [...] sugerir terapia, fono, atendimento psicológico. O problema é [...] vai mandar para onde? [...] Ou começa a partir de uma determinada idade, particularmente, o Betina [hospital universitário] está inchado. Porque, assim, a gente sugere.... Então, é muito complicada a questão do encaminhamento. A gente sugere sim o encaminhamento para a família. Sugere mesmo, às vezes consta [...] a gente sugere para uma colega incluir, mas é muito complicado. (E104, grifo nosso).

Pêcheux (2006, p. 54) afirma que a relação entre descrição e interpretação pode ser caracterizada como um "batimento": não são a mesma coisa, mas não se separam. No debate sobre a avalia- ção conjunta do rendimento do aluno, em E59, chamamos a atenção para o adversativo colocado entre a repetição do "muitas vezes", produzindo um efeito de sentido de que o trabalho conjunto é mais um desejo (um "vislumbre") do que uma prática consistente:

Atualmente a gente já consegue estar junto com o professor para tomar esse processo de decisão.

Muitas vezes, nem toda vez, mas muitas vezes, nós somos solicitados para estar lá e fazer parte dessa discussão. Atualmente a gente já vislumbra isso, há algum tempo atrás, não. Era decidido e pronto. (E59, grifo nosso).

Lidando com aquilo que Pêcheux (1997, p. 167) chama de intradiscurso, definido por ele como "o funcionamento do discurso com relação a si mesmo (o que eu digo agora, com relação ao que eu disse antes e ao que direi depois; portanto, o conjunto dos fenômenos de co-referência que garantem aquilo que se pode chamar o 'fio do discurso')", percebemos vários movimentos contraditórios. A exigência de especialização, assumida como fundamental para o trabalho docente nas salas de recursos, se defronta com a percepção de que os cursos teóricos não dão conta da complexidade da prática: "Porque no caso, quando a gente faz uma especialização direcionada à Educação Especial, quando a gente chegar na prática, aquela especialização, a gente vê que não suporta o que a gente vai atender realmente" (E2, grifo nosso).

O fio do discurso, para ser acompanhado, exige que o referente (inclusão) seja lido não em suas condições reais, mas em sua idealização, como no enunciado a seguir. A condição para a avaliação dar certo se depara com a exigência de uma família que tenha acesso aos médicos e esteja atenta não apenas para perceber as limitações, mas tenha conhecimento de desenvolvimento infantil.

A avaliação tem um grande avanço quando a família percebe e antes busca um médico e não fica naquela avaliação [...]. Às vezes é difícil dar uma avaliação diagnóstica quando tem uma idade muito pequena [...] infantil. Então, assim, quando já vem com o encaminhamento da família é mais fácil da gente conseguir o desenvolvimento da criança, mas muitas vezes... É percebida a dificuldade pela escola, a gente vai fazer contato. Sempre na avaliação tem a avaliação da criança, o contato com o responsável. 
É feita a entrevista familiar. A gente percebe, como ela [...] falou na gravidez, no desenvolvimento, que a criança tem um atraso desde que nasceu. [...] Mas você vai fazer a entrevista familiar e você percebe que a criança teve dificuldade em tudo. Tem dificuldade em tudo. Desenvolvimento. Ah, tem dificuldade de linguagem. Demorou para sentar, demorou para sustentar o pescoço para engatinhar, para andar. Então, na família já tem assim [...] (E100, grifo nosso).

O sentido da evidência também faz parte das condições de produção do discurso. A inclusão escolar da pessoa em situação de deficiência entra na condição de "acontecimento discursivo", atualizando a memória da educação especial como o que "tem que ser", porque é melhor, mais democrático, mais avançado, novo etc. Acontecimento discursivo que é retomado incessantemente, no empenho de constituir a si mesmo pela linguagem; esse empenho discursivo denuncia os riscos de deixar de ser na concretude, pelas condições reais das escolas e da família, pela perda de status ao se deslocar do lugar do clínico para a lugar da escolarização, pela disputa de espaços e verbas públicas pelos setores privados e, dentro dos setores públicos, pelas políticas de assistência, entre outros enfrentamentos.

O movimento interpretativo que ressoa nas descrições do que é, do que tem que ser, evoca aquilo que ainda não é, ou aquilo que não pode ser porque as condições concretas não permitem. Tal interpretação é lida por nós como tomada de posição, conforme apontava Pêcheux (2006, p. 57):

A posição de trabalho que aqui evoco [...] supõe somente que, através das descrições regulares de montagens discursivas, se possa detectar os momentos de interpretações enquanto atos que surgem como tomadas de posição, reconhecidas como tais, isto é, como efeitos de identificação reconhecidos e não negados.

É nas tomadas de posição que se pode encontrar os enfrentamentos entre os discursos autoritário e polêmico que disputam espaço no discurso pedagógico. Para concluir esse tópico, no qual buscamos analisar como a interdiscursividade se desenha nos enfrentamentos presentes na memória docente (enfrentamentos que se constituem nas condições de produção do discurso, mas também no seu acontecimento), vemos que o lugar de especialista se esgarça ao se situar no campo pedagógico, cujas exigências são de generalista; que as descrições do outro professor como pouco esclarecido implica na fragilização da tarefa conjunta a ser empreendida por professores especialistas e de sala comum; que os lugares de saber especializado, pelas impossibilidades da própria prática docente, passam a se amparar em lugares do saber cotidiano. $\mathrm{O}$ discurso pedagógico, por um lado, se fortalece em seus aspectos autoritários e tem reduzidas suas possibilidades polêmicas, na disputa da polissemia em torno das especialidades. Por outro lado, as próprias impossibilidades semânticas apontam brechas para polêmica: como ser especialista em praticamente tudo? Anuncia-se uma formação discursiva que se organiza em torno da polêmica, anunciando possibilidades estratégicas que fazem deslizar para o questionamento dos lugares fixos de quem sabe e quem não sabe, dos saberes definitivos acerca da inclusão.

Também o uso de certas modalidades enunciativas, como a definição e a naturalização, organiza de certo modo o dizer acerca da inclusão. No caso da definição, temos as tentativas de explicar o que é (e o que não é) sala de recursos, de como é o aluno que ali se encaixa (ou não), do que significa ser especialista (se assim pudesse ser). A naturalização aplica-se como movimento discursivo quando as desigualdades sociais (que fazem com que as famílias não possam arcar com os custos da inclusão) são descritas como questões externas, não compondo o cenário de exclusão que justificaria um esforço inclusivo. Também são naturalizadas as características que seriam necessárias a um curso de formação que precisaria responder a todas as especificidades da deficiência. O modo de operar discursivo desloca, por tais modalidades, a descrição do real para uma descrição do que não é, mas deveria ser (ou é real, mas não aceito como verdadeiro). Assim, deslizam os conceitos de inclusão, de educação especial, de sala de recursos; os lugares de especialista, docente, aluno; as relações entre tais lugares e conceitos, produzindo efeitos de sentido não previstos e elaborando saberes não esperados. $\mathrm{Na}$ condição de acontecimento, o discurso pedagógico sobre inclusão escolar esgarça o próprio lugar na estrutura da produção discursiva. 


\section{Formação imaginária e acontecimento discursivo: a título de conclusão}

A título de conclusão deste percurso investigativo, cabe aqui retomar os principais aspectos levantados no trabalho analítico em torno da produção discursiva sobre inclusão.

Apontamos, naquela leitura inicial, uma polarização entre a luta pelo direito à educação e a tradição assistencialista, a qual associamos à política do Estado mínimo. Entender a sala de recursos como único suporte da inclusão faz sentido na lógica desse Estado mínimo. Nos enunciados analisados, o discurso pedagógico autoritário justifica tal modelo e se empenha por explicar as falhas pela ausência de especialistas adequados, pela inadaptação dessa redução da instituição assistencial a um espaço no interior da escola. Já o discurso polêmico aponta as impossibilidades do modelo, recuperando indícios de uma leitura das condições concretas da escola e propondo a ampliação da ação do Estado.

O embate entre discurso autoritário e discurso polêmico se organiza numa formação discursiva contraditória, em que o discurso médico, ao se sobrepor ao discurso pedagógico, produz faltas e ausências estranhas a este. No estranhar a falta de determinados saberes, próprios das especializações do campo clínico, desvaloriza a presença de saberes próprios das vivências pedagógicas. Oriundo de uma posição social de maior status, acostumado com as assimetrias de poder, o discurso médico desloca o discurso pedagógico para seu viés autoritário. Lembremos da principal característica de tal discurso como proposto por Orlandi (2003, p. 9): “A contenção da polissemia, já que o agente do discurso se pretende único e oculta o referente pelo dizer". O referente "inclusão" perde sentidos oriundos da forma concreta como é vivido, para ser substituído por definições livrescas ou normativas. A deficiência se oculta enquanto produção cultural para ressurgir como estigma, como problema daquele que a vive.

A formação discursiva que rejeita tal discurso se organiza em torno do questionamento dos lugares fixos, dos saberes definitivos acerca da inclusão escolar da pessoa com deficiência: fornece ao discurso pedagógico possibilidades polêmicas e estratégias de recuperação de seu lugar no interior da escola, espaço pedagógico por definição. Tal formação discursiva permite visualizar outras faltas: falta de condições para o ensino, ausência de utilização dos saberes do cotidiano escolar e da vivência coletiva como forma de reorganizar o acontecimento discursivo da inclusão. Discurso polêmico, no qual o referente "inclusão" é redescrito e reinterpretado em suas contradições, em suas relações com o contexto político e com as condições concretas da educação brasileira.

\section{REFERÊNCIAS}

AULETE DIGITAL. Especialista. Disponível em: <http://www.aulete.com.br/especialista $>$. Acesso em: 23 mar. 2017.

AUTHIER-REVUZ, Jacqueline. Heterogeneidade(s) enunciativa(s). Cadernos de Estudos Linguísticos, n. 19, p. 25-42, jul./dez. 1990.

BAPTISTA, Cláudio R. Ação pedagógica e educação especial: para além do AEE. In: BAPTISTA, C. R.; CAIADO, K. R. M.; JESUS, D. M. Práticas pedagógicas e inclusão: multiplicidade do atendimento educacional especializado. Araraquara, SP: Junqueira e Marin, 2013.

BRASIL. Política Nacional de Educação Especial na Perspectiva da Educação Inclusiva. Brasília, DF: MEC/ SEESP, 2010.

CAIADO, Kátia Regina Moreno. Aluno deficiente visual na escola: lembranças e depoimentos. Campinas, SP: Autores Associados/PUC-SP, 2006.

CESÁRIO, A. C. C.; ALMEIDA, A. M C. Discurso e ideologia: reflexões no campo do marxismo estrutural. Acta Scientiarum - Human and Social Sciences, Maringá, PR, v. 32, n. 1, p. 1-8, 2010.

DICIO. Dicionário Online de Português. Encaixe. Disponível em: <https://www.dicio.com.br/>. Acesso em: 20 mar. 2015. 
DINIZ, Débora. O que é deficiência. São Paulo: Brasiliense, 2007.

DINIZ, Débora; BARBOSA, Lívia. Definições - um gesto político para nominar o silêncio. Disponível em: <http:// nau.fflch.usp.b/sites/nau.fflch.usp.br/files/upload/paginas/Diniz_Barbosa>. Acesso em: 10 fev. 2013.

GARCIA, Rosalba Maria Cardoso. Política de educação especial na perspectiva inclusiva e a formação docente no Brasil. Revista Brasileira de Educação, v. 18, n. 52, p. 101-119, jan./mar. 2013.

GIORGENON, Daniela; ROMÃO, Lucília Maria Sousa. O autoritário no discurso pedagógico e a inclusão do heterogêneo. Psicologia em Revista, Belo Horizonte, v. 19, n. 2, p. 271-286, ago. 2013.

GLAT, Rosana. Somos iguais a vocês: depoimentos de mulheres com deficiência mental. Rio de Janeiro: Agir, 1989.

GLAT, Rosana; PLETSCH, Márcia Denise. O método de história de vida em pesquisas sobre autopercepção de pessoas com necessidades educacionais especiais. Revista Educação Especial, Santa Maria, RS, v. 22, n. 34, p. 139-154, maio/ago. 2009. Disponível em: <http://www.ufsm.br/revistaeducacaoespecial>. Acesso em: 01 jun. 2015.

MAINGUENEAU, Dominique. Novas tendências em análise de discurso. Campinas, SP: Editora da Unicamp, 1997.

MENDES, Enicéia Gonçalves; PICCOLO, Gustavo. Contribuições a um pensar sociológico sobre a deficiência. Educação e Sociedade, Campinas, SP, v. 34, n. 123, p. 459-475, abr./jun. 2013.

NABUCO, Maria Eugênia. Práticas institucionais e inclusão. Cadernos de Pesquisa, v. 40, n. 139, p. 63-74, abr. 2010. OBSERVATÓRIO NACIONAL DE EDUCAÇÃO ESPECIAL (ONEESP). São Carlos, SP, 2013. Disponível em: $<\mathrm{http}$ ://www.oneesp.ufscar.br/>. Acesso em: 21 mar. 2015.

ORLANDI, E. P. A linguagem e seu funcionamento: as formas do discurso. São Paulo: Brasiliense, 2003.

. Análise de discurso: princípios e procedimentos. 5. ed. Campinas, SP: Pontes, 2005a. 9-13, 2005b.

Michel Pêcheux e a análise de discurso. Estudos da Língua(gem), Vitória da Conquista, BA, v. 1, p.

. Nota ao Leitor. In: PÊCHEUX, M. O discurso: estrutura ou acontecimento. Trad. Eni P. Orlandi. 4. ed. Campinas, SP: Pontes, 2006. p. 7-9.

PAULA, Fernando Silva; TFOUNI, Leda Verdiani. A persistência do fracasso escolar: desigualdade e ideologia. Revista Brasileira de Orientação Profissional, São Paulo, v. 10, n. 2, p. 117-127, dez. 2009. Disponível em: $<$ http://pepsic.bvsalud.org/pdf/rbop/v10n2/v10n2a12.pdf>. Acesso em: 26 abr. 2017.

PÊCHEUX, Michel. Semântica e discurso: uma crítica à afirmação do óbvio. Trad. Eni P. Orlandi et al. 3. ed. Campinas, SP: Editora da Unicamp, 1997.

PÊCHEUX, Michel; FUCHS, Catherine. A propósito da análise automática do discurso: atualização e perspectivas (1975). In: GADET, Françoise; HAK, Tony (Org.). Por uma análise automática do discurso: uma introdução à obra de Michel Pêcheux. 3. ed. Campinas, SP: Editora da Unicamp, 1997. p. 163-252.

O discurso: estrutura ou acontecimento. Trad. Eni P. Orlandi. 4. ed. Campinas, SP: Pontes, 2006.

SANTIAGO, Mylene Cristina; SANTOS, Monica Pereira. Planejamento de estratégias para o processo de inclusão: desafios em questão. Educação e Realidade, Porto Alegre, v. 40, n. 2, p. 485-502, abr./jun. 2015.

SILVEIRA, Kelly Ambrósio; ENUMO, Sônia Regina Fiorim; ROSA, Edinete Maria. Concepções de professores sobre inclusão escolar e interações em ambiente inclusivo: uma revisão da literatura. Revista Brasileira de Educação Especial, Marília, SP, v. 18, n. 4, p. 698-705, out./dez. 2012.

Recebido: 08/05/2017

Aprovado: 10/10/2017 